\title{
QUALITY OF LIFE AFTER TOTAL GLOSSO-LARYNGECTOMY
}

\author{
Leanie Engelbrecht and Anita van der Merwe
}

Department of Communication Pathology, University of Pretoria

\section{ASTRACT}

The article explores the quality of life of two participants who had undergone total glosso-laryngectomy as treatment for advanced tongue base cancer. Semi-structured interviews were conducted and questions relating to the effects of treatment on physical, functional, social and psychological well-being were asked. Thematic analysis of the interviews was done to determine recurring themes in the answers of the participants. The findings showed that total glosso-laryngectomy has a significant impact on quality of life. A good quality of life can be maintained in a patient who has an extensive support structure and can achieve intelligible oral communication. Pre-operative counselling by a multi-disciplinary team is important for a person to make an informed decision regarding surgery for head and neck cancer. Shared decision making needs to be addressed in the South African service delivery context.

Key Words: Quality of life, physical well-being, functional well-being, social well-being, emotional/psychological well-being, glossectomy, glosso-laryngectomy

\section{INTRODUCTION}

In 1947 the World Health Organisation's definition of health changed from "absence of disease and infirmity" to "a state of physical, mental and social well-being" (World Health Organisation, 1997). This definition emphasises the value of preserving physical, social and mental health. Quality of life for head and neck cancer patients has become a much debated topic and a crucial area of research in the last two decades (Major, Bumpous, Flynn \& Schill, 2001; Petruson, Silander \& Hammerlid, 2003). The reason for this interest in quality of life of a person who has head and neck cancer is that treatment of this type of cancer may be curative, but may also have a dramatic effect on many aspects of life for such a person. The person who receives the diagnosis of head and neck cancer has to make an informed decision regarding treatment. The speechlanguage pathologist will in many instances be an important resource for information regarding the consequences of treatment and therefore needs to be informed of the possible effect of surgery for head and neck cancer on quality of life.

Surgical treatment for advanced head and neck cancer often entails total glossectomy and total glosso-laryngectomy (Harrison, Ferlito, Shaka, Bradley, Genden \& Rinaldo, 2003). $\mathrm{T} 1$ tumours $(2 \mathrm{~cm}$ or less in greatest dimension) and T2 tumours (more than $2 \mathrm{~cm}$ but not more than $4 \mathrm{~cm}$ in greatest dimension) can be treated with a single modality, for example, surgery or radiotherapy. T3 tumours (more than $4 \mathrm{~cm}$ in greatest dimension) and T4 tumours (extensive tumour infiltrating adjacent structures), however, may require combined treatment such as surgery followed by radiotherapy or chemoradiation (Shah, 1996; Harrison et al., 2003). When surgery is the treatment modality of choice, total glossectomy may be performed. A laryngectomy may also be performed concomitant with total glossectomy to prevent aspiration of liquids and food that may follow after total glossectomy (Davidson, Brown \& Gullane, 1993). In extensive tumours where the valleculae and/or larynx are infiltrated, total laryngectomy has to be performed together

Department of Communication Pathology

University of Pretoria

Pretoria

0002

South Africa

E-mail: leanie.2305@vodamail.co.za or anita.vandermerwe@up.ac.za with the glossectomy to obtain clear surgical margins. This operation is known as a total glosso-laryngectomy.

Although surgery for base of the tongue cancer is often life saving, this type of surgery may lead to various problems post-operatively, thereby affecting the patient's quality of life. Despite advanced reconstruction techniques and methods of rehabilitation, total glossectomy patients are still faced with deficits in eating, speaking, breathing, shoulder movement and also deformed physical appearance (Ruhl, Gleich \& Gluckman, 1997; Vickery, Latchford, Hewison, Bellew \& Feber, 2003). If a total laryngectomy is performed too, the person will not only lose the tongue, but also the ability to produce voice. Total glossectomy and total glosso-laryngectomy may impact on physical well-being, social well-being, psychological wellbeing and functional status (Chen, Frankowski, Bishop-Leone, Hebert, Leyk, Lewin \& Goepfert, 2001; Morton, 2003).

The term health related quality of life (HRQoL) is frequently used to focus on the clinical effects of a disease and its treatment. This concept highlights those aspects of life that are affected by healthcare interventions (Fayers \& Machin, 2000; Ferlito, Rogers, Shaha, Bradley \& Rinaldo, 2003). The exact meaning of the term HRQoL has not been adequately defined and according to Fayers and Machin (2000) the aspects that the term encompasses may vary from study to study. The term quality of life refers to a broader scope of aspects than pure clinical effects as encompassed in HRQoL. Quality of life has been described as a broad concept that applies to a person's general well-being and life-satisfaction (Walter \& Shannon, 1990). According to Morton (2003) quality of life relates to a range of physical and psychological parameters that describe an individual's ability to function and derive satisfaction from life. To make sense of the many aspects of quality of life, some main components of quality of life has been suggested.

According to Morton (2003) the components of quality of life can be divided into four domains, namely physical functioning, social interaction, psychological state and somatic sensation. Fayers and Machin (2000) state that general health, physical functioning, physical symptoms, emotional functioning, cognitive functioning, role functioning, social well-being and functioning, sexual functioning and existential issues are components of quality of life. Five broad domains of HRQoL are identified by Gift and Atchison (1995) and these are: op- 
portunity/resilience, health perception, functional status, impairments/disease and duration of life. Fang, Tsai, Chien, Chiu, Wang, Chen and Hsiung (2005) explain that quality of life has two fundamental premises. First, it is a multidimensional survey incorporating physical, functional, social, emotional and psychological domains. Second, it is subjective and must be selfreported according to the patient's own experience. These conceptualisations of quality of life (or HRQoL) encompass the three dimensions specified by the ICIDH-2 classification of the consequences of health conditions. These dimensions are: The Body dimension which "comprises two classifications, one for functions of body systems, and one for the body structure"; The Activities dimension which includes "the complete range of activities performed by the individual"; And the Participation dimension which "classifies areas of life in which an individual is involved, has access to, and/or for which there are societal opportunities or barriers" (WHO, 2007 p.1).

Many self-completion questionnaires for assessing quality of life of head and neck cancer patients are available (Ferlito et al., 2003). Established and well-known instruments for quality of life assessment in head and neck cancer patients include the following: Functional Assessment of Cancer Therapy Head and Neck Version (FACT HN); Performance Status Scale for Head and Neck Cancer (PSS HN); University of Washington Quality of Life Questionnaire (UWQOL); The Sickness Impact Profile (SIP); European Organisation for Research and Treatment of Cancer Core Questionnaire - Head and Neck Module (EORTC HN); Life Satisfaction Scale (LSC); Head and Neck Radiotherapy Questionnaire (HNRQ); Locus of Control (LOC); The General Health Questionnaire (GHQ) (Ferlito et al., 2003). The majority of quality of life questionnaires include a global quality of life measurement as well as focus on disease- and treatment specific outcomes and psychosocial issues. Areas of quality of life that are usually assessed by quality of life instruments for patients with head and neck cancer, include physical-, functional-, social-, and emotional- or psychological well being (Pretorius, 2004). These dimensions are also used in the current study. Thus a model that encompasses all levels of functioning and disability (WHO, 2007) as determinants of quality of life is adopted in this study.

Patients with head and neck cancer face many consequences of this disease and its treatment. First of all there is the fear of death and dealing with the knowledge of having a lifethreatening disease (Vickery et al., 2003). Head and neck cancer patients have many of the same risk factors for suicide as patients with other forms of cancer. It has been well documented that patients with a diagnosis of cancer are at increased risk of committing suicide (Henderson \& Robert, 1997). Surgery may result in visible and extensive facial and neck disfigurement. Facial disfigurement is one of the most potentially distressing aspects of head and neck cancer because of the vital importance of the facial region to self-concept, interpersonal relationships and communication (Katz, Irish, Devins, Rodin \& Gullane, 2003). Katz et al. (2003) found that head and neck cancer patients with greater facial disfigurement were more depressed than patients with less facial disfigurement. Similarly, Gamba, Romano, Grosso, Tamburini, Cantu, Molinari and Ventafrida (1992) found a significantly higher impact in head and neck cancer patients with extensive disfigurement versus head and neck cancer patients with minor disfigurement with regard to changed self-image, a worsened relationship with a partner, reduced sexuality, and increased social isolation. Functionally, swallowing, speech and the ability to work may be affected. One of the main factors that influence the perception of quality of life of head and neck cancer patients, is their ability to eat and swallow normally (Kendall \& Leonard, 1999; Hutton \& Williams, 2001). In almost all cultures eating is a social activity and patients who are not able to eat normally may withdraw from these activities. Morton (2003) also stated that life satisfaction scores for head and neck cancer patients were related to pain, dysphagia and speech difficulty. Prolonged disability and the cost of treatment threaten the socio-economic stability of patients and their families and patients fear that they may become a social and financial burden (Vickery et al., 2003). The effects of surgery, radiotherapy and chemotherapy can lead to limitation of social activities, a delayed return to work and feelings of isolation (Vickery et al., 2003). Quality of life in head and neck cancer patients will thus encompass many parameters such as survival, pain, aesthetics, functional changes, job changes and social and existential issues.

Quality of life has been explored in several head and neck cancer populations overseas, but only a few studies have been done regarding the quality of life of patients who have undergone total glossectomy (Davidson et al., 1993; Ruhl et al., 1997). With regard to total glosso-laryngectomy no such studies have been undertaken. In South Africa patients are often diagnosed with advanced head and neck cancer and extensive surgery may be the only treatment option. The issue of debate is whether the quality of life after operations such as total glossectomy and total glosso-laryngectomy justify this drastic surgery. The answer to this question is of the utmost importance as it has implications for the patient who is going to have a total glossectomy or glosso-laryngectomy. In order to survive, patients are often willing to tolerate any form of surgery. If a good quality of life can be achieved, it makes the use of these radical procedures more acceptable to the patient and the surgeon. Morton (2003) emphasised that patients may learn to cope well with dysfunction and disability by adjusting their lifestyle so that overall quality of life was not related to the treatment received. Functional status and quality of life are thus not equivalent, and function itself cannot predict quality of life (Ruhl et al., 1997). Therefore, observed dysfunction, disability and disfigurement do not necessarily reflect the patients' rating of their own quality of life. Also in total glossectomy and total glossolaryngectomy patients, one should be careful not to equal postoperative functioning with quality of life. It is possible that a patient could be content with his/her quality of life, postoperatively. A patient may feel that functional restrictions are bearable in the light of survival and may adapt well to functional changes. It is therefore necessary to obtain information regarding quality of life as experienced by patients themselves.

Information with regard to factors that affect postoperative adaptation is thus of the utmost importance as it has implications for pre-operative counselling as well as postoperative support. If the multidisciplinary rehabilitation team, including the speech-language pathologist, is aware of the factors that may influence quality of life, the team will be better equipped for appropriate pre-operative counselling and postoperative psychosocial support. A well-prepared patient may also adapt better post-operatively than an unprepared patient. Feedback from the patient in terms of quality of life may thus influence surgeons' choices and speech-language pathologists' rehabilitation practices.

\section{METHOD}

\section{Aim}

The aim of this study was to determine the quality of life of two participants who had undergone total glosso-laryngectomy. 


\section{Research Design}

A qualitative research design was followed in the form of two case studies (parallel case studies) of patients who had undergone total glosso-laryngectomy. Case studies refer to qualitative studies of one or a few illustrated cases. It is a method involving systematically gathering enough information about a particular person, social setting, event or group to permit the researcher to effectively understand how the subject operates or functions (Berg, 2007). Information regarding quality of life was obtained from the two participants through semi-structured/semi-standard face-to-face interviews and open-ended questions were asked (Terre Blanche \& Durrheim, 1999; Berg, 2007,).

Berg (2007) explains that the semi-standard interview is more or less structured, that questions may be recorded during the interview, that the wording of questions are flexible, that the level of language may be adjusted, that the interviewer may answer questions and make clarifications and that the interviewer may add or delete probes during the interview. According to Patton (1990) semi-structured interviewing begins with the assumption that the perspective of others is meaningful. The object of such interviews is to get the person being interviewed to talk about their experiences, feelings, opinions and knowledge (Patton, 1990). Open-ended questions are utilised in order to encourage the participants to identify areas of importance to them, using their own vocabulary (Patton, 1990).

\section{Materials and Methods}

The researcher developed an interview schedule (Appendix A) containing a set of questions regarding different domains of quality of life (Neumann, 2000). A topic guide ensured that the same information was obtained from both participants (Patton, 1990). The interview-questions were designed according to information obtained from the literature regarding quality of life in head and neck cancer patients. The interview schedule included questions about physical-, functional-, social- and emotional/psychological well-being.

The interview schedule was used to direct the interviews with the participants, but the wording and order of the questions were not fixed (Patton, 1990). Questions were asked in the participants' first language. Multiple and leading questions were avoided to limit any suggestions of a desired answer from the subject (Terre Blanche \& Durrheim, 1999). The interviews were conducted in the office of the researcher (first author) by the researcher. The interviews were recorded on a high quality Panasonic RQ-L10 tape recorder. Audio recording of the interview sessions allowed both the researcher and the participant to cross check the data gathered, thus enabling a means of validating the data. Participant 1, who was non-verbal, communicated by means of writing. During this interview, the speech of the researcher was tape-recorded to ensure complete transcription of the interview. The researcher transcribed the recordings and listened to the tapes several times to ensure that all data were transcribed correctly.

\section{Participant Selection Criteria}

The following selection criteria were set: The participant should have undergone total glosso-laryngectomy; should not have suffered from any other medical condition than the glossolaryngectomy; should not have had any other communication disorder; and should have been Afrikaans or English speaking as these were the languages in which the interviewer could conduct an interview.

\section{Participants}

Both participants were patients at an academic hospital in Gauteng at the time of the study. This was an example of a purposive or judgmental sampling, where anyone in a hard-tofind target population was selected (Neumann, 2000). At the time of the study there were only two surviving total glossolaryngectomy patients that could be tracked in the Gauteng region. Participant 1 had surgery six weeks prior to the time of the interview and Participant 2, seven years prior to the interview.

Participant 1 was a 51-year-old Afrikaans speaking white male who had a T4N3M0 squamous-cell carcinoma of the tongue-base and larynx. He underwent a total glossolaryngectomy and bilateral radical neck dissections on the $4^{\text {th }}$ of February 2004. The oral cavity was reconstructed with a Pectoralis Major musculo-cutaneous flap. The interview was conducted on the $23^{\text {rd }}$ of March 2004. The patient's course of radiotherapy began on the $29^{\text {th }}$ of March 2004. The patient made use of facial expressions and gestures to augment written communication. At the time of the interview the participant was divorced, had lost his job as a security inspector and had poor social support. He was from a low socio-economic income group.

Participant 2 was a 63-year-old Afrikaans speaking white male who had a T4N3M0 squamous-cell carcinoma of the tongue-base and larynx. He underwent a total glossolaryngectomy and bilateral radical neck dissections on the $2^{\text {nd }}$ of December 1996. A Provox Prosthesis that makes tracheoesophageal voice production possible was inserted at the time of the operation. The participant received a six-week course of radiotherapy post-operatively. The interview was conducted on the $9^{\text {th }}$ of March 2004. The participant was a very lively communicator. His speech was fairly intelligible. He made use of a slow speech rate, intonation, eye contact, gestures and facial expressions to augment his speech. At the time of the interview the participant was married, resumed his work and had an excellent support structure. He was from an average socioeconomic income group. A summary of the participants' characteristics is shown in Table 1.

Table 1: Description of the two participants

\begin{tabular}{|l|l|l|}
\cline { 2 - 3 } \multicolumn{1}{l|}{} & \multicolumn{1}{|c|}{ Participant 1 } & \multicolumn{1}{c|}{ Participant 2 } \\
\hline Age & 51 years & 63 years \\
\hline Gender & Male & Male \\
\hline Race & White & White \\
\hline Language & Afrikaans & Afrikaans \\
\hline $\begin{array}{l}\text { Treatment received at } \\
\text { time of interview }\end{array}$ & $\begin{array}{l}\text { Total glosso- } \\
\text { Bilateral radical neck } \\
\text { dissections }\end{array}$ & $\begin{array}{l}\text { Total glosso- } \\
\text { laryngectomy } \\
\text { dissections } \\
\text { Post-operative radio- } \\
\text { therapy }\end{array}$ \\
\hline $\begin{array}{l}\text { Time span since sur- } \\
\text { gery }\end{array}$ & Six weeks & Seven years \\
\hline $\begin{array}{l}\text { Voice prosthesis in- } \\
\text { serted }\end{array}$ & No & Yes \\
\hline Functional speech & No & Yes \\
\hline Swallowing & Oral (liquid diet) & Oral (liquid diet) \\
\hline Work & Unemployed & Employed \\
\hline Social support & Poor & Good \\
\hline Socio-economic group & Low & Average \\
\hline
\end{tabular}




\section{Data analysis}

Content analysis is a careful, detailed, systematic examination and interpretation of a particular body of material in an effort to identify patterns, themes, biases, and meanings (Berg, 2007). Thematic analysis of the content of the interviews was conducted at five levels, according to the guidelines of Patton (1990) and Terre Blanche and Durrheim (1999). Terre Blanche and Durrheim (1999) describe the process of data analysis as reading through your data repeatedly, and engaging in activities of breaking the data down (thematising and categorising) and building it up in novel ways (elaborating and interpreting). During this process the researcher steered clear of imposing prior theoretically derived concepts on the data. Instead, careful inspection of the narrative facilitated the generation and development of new concepts from the research data via an inductive analysis.

The following steps were followed: Familiarisation and immersion: The researcher read through the data repeatedly and intensely. Relevant information was selected, irrelevant information was eliminated, key words were identified and notes were made during the reading of the data. A summary was made of each of the components of the interview schedule (general information, physical well-being, functional well-being, social wellbeing and emotional/psychological well-being). Inducing themes (in relation to the research question): The researcher identified the organising principles that "naturally" emerged from the data. This was done by inductive analysis, meaning that themes emerge from the data as opposed to themes being imposed on the data prior to data analysis. Coding: Coding means breaking data up in analytically relevant ways. The copy-and-paste function of a word processor program was used to move bits of text around to fit the identified themes. Elaboration: Elaboration means the discovery of new dimensions of the subject that are being studied or looking at data in a fresh way. Comparisons were made of sections of text that appeared to belong together and comparisons were made between themes identified from the two interviews. Interpretation and checking: Themes were discussed in relation to available literature.

\section{Ethical considerations}

Before initiating the research, the researcher received ethical clearance for the research project from the Research and Ethics Committee of the Human Sciences Faculty of the University of Pretoria. Written informed consent was obtained from both participants and ethical issues regarding tape recording of interviews, anonymity, confidentiality and withdrawal from the research project were discussed. Both participants gave consent that results of the study may be published. Both participants were patients of a speech therapy department at an academic hospital and support- and follow-up services were available.

\section{Trustworthiness}

Measures to ensure trustworthiness that were implemented in this qualitative study included, truth-value, applicability, consistency and neutrality (De Vos, 2002).

Truth-value establishes how confident the researcher is with the truth of the findings, based on the research design, informants, and context (De Vos, 2002). On the research design level, truth-value was established by designing the interview schedule according to information obtained from the literature regarding quality of life in head and neck cancer patients. Semistructured interviews, which are an acknowledged tool in quali- tative research, were conducted in the participants' first language (Afrikaans) to allow for free expression. Interviews were recorded to permit transcription of every utterance. Participant 1 wrote down his answers. All the answers of Participant 2 were transcribed and unintelligible utterances were later verified with him. In the results direct quotes (translated into English for the purpose of publication of the data) from the transcribed data are presented.

Applicability refers to the ability to generalise from the findings to the greater population (De Vos, 2002). One perspective on applicability in qualitative research suggests that the ability to generalise is not relevant in many qualitative research projects. Results of case studies can to some extent be generalised, but it was not the intent to generalise the findings of this study to the greater population of total glosso-laryngectomy patients. Each person's situation is unique and there are different variables that may influence quality of life after total glossolaryngectomy. Since total glosso-laryngectomy is such a radical surgical procedure with very specific effects on function, it is possible that some of the experiences may be similar in persons who have undergone total glosso-laryngectomy. Berg (1997) is of the opinion that case studies could not only represent the specific individual, group or event studied, but could also provide understanding about similar individuals, groups or events.

Consistency indicates whether the finding would be consistent if the enquiry were replicated with the same subject or in a similar context (De Vos, 2002). This study can be viewed as consistent, as an interview schedule with a specific topic guide was used to obtain the information. The themes that emerged from the different questions were checked with the participants to assure that the message that the participant was conveying to the interviewer was understood correctly.

Neutrality refers to the degree to which the findings are a function solely of the informants and conditions of the research and not of other biases, motivations and perspectives (De Vos, 2002). Questions were asked in such a way that it should not have influenced the answers of the participants. The researcher merely determined and reported the views, perspectives and feelings of the participants. To establish whether the categories, explanations and interpretations of the data were reliable, the data were also analysed by a clinical psychologist with a doctoral degree and who has experience in qualitative research studies and content analysis. The themes that were identified by the researcher and the conclusions were discussed with the psychologist, and a few discrepancies were resolved.

\section{RESULTS AND DISCUSSION}

The most prominent themes that emerged from the thematic analysis are described and discussed in this section. The themes are summarised in Table 2. For the purpose of gaining a comprehensive view of the experiences and feelings of the two participants, the original categories of the interview schedule namely physical-, functional-, social- and emotional/psychological wellbeing will be slightly adapted. Experiences in these different domains interact and it may be artificial to categorise them according to the theoretical guidelines that were followed in the interview schedule. Themes that do not fit any of the original categories emerged and these will also be described.

\section{Functional well-being}

\section{Speech and communication}

At the time of the interview, which was six weeks postsurgery, Participant 1 was still not able to communicate verbally 
Table 2: Summary of quality of life as perceived by the two participants

\begin{tabular}{|l|l|l|}
\hline \multicolumn{1}{|c|}{ Theme } & \multicolumn{1}{c|}{ Participant 1 } \\
\hline Speech & Non-verbal, feelings of isolation, uselessness & $\begin{array}{l}\text { Has functional speech and that enhanced integration into } \\
\text { the community }\end{array}$ \\
\hline Workffinances & Unemployed - affected self-image negatively & Employed - affected self-image positively \\
\hline $\begin{array}{l}\text { Perception of other peoples' reaction towards } \\
\text { them }\end{array}$ & Very aware and sensitive, perceived reaction as rejection & Ambivalent (in the process of becoming less sensitive) \\
\hline Isolation & $\begin{array}{l}\text { Prefer to be alone, avoid people, but also want to make } \\
\text { contact with people }\end{array}$ & $\begin{array}{l}\text { Part of the community (progressed from isolation to } \\
\text { integration) }\end{array}$ \\
\hline Acceptance and support & Little acceptance/support & $\begin{array}{l}\text { Accepted by most significant others and excellent support } \\
\text { structure }\end{array}$ \\
\hline Changed self-image & Perceives himself as abnormal & Perceives himself as abnormal \\
\hline Adjustment & Patient still in the process of adjustment, poor coping skills & Patient has adjusted well and has overcome most problems \\
\hline Overall/global quality of life & Poor & Good \\
\hline Pre-operative counselling & Patient not counselled prior to surgery & Patient partially prepared for surgery and its effects \\
\hline Role of the speech-language pathologist & $\begin{array}{l}\text { Speech rehabiliation } \\
\text { Swallowing rehabilitation } \\
\text { Support }\end{array}$ & $\begin{array}{l}\text { Speech rehabilitation } \\
\text { Swallowing rehabilitation }\end{array}$ \\
\hline
\end{tabular}

and this circumstance had far reaching consequences. The inability to speak resulted in him losing his job and led to high levels of frustration. Being a security-inspector, he relied on verbal communication. The inability to speak also prevented him from fully expressing his thoughts, feelings and desires. Communication needs could only be fulfilled in a limited way by writing. He said:

'I will never be able to speak again. It is incredibly difficult to be suddenly mute - after 51 years of talking. It is a strange world. Totally strange. Because I can't speak I have lost $m y$ job and I am struggling financially. Without speech I am useless to the company, because I have to speak with a radio control as well as to clients.'

Participant 2 experienced the same problem initially, but his life changed since he learned to speak. He could express his feelings, resume his work with greater ease and frustration was reduced. He expressed his experience of the loss of speech as follows: .

\section{'In the beginning it was difficult to communicate be- cause nobody understood me. Everywhere I went as well as at work I had to write if I wanted to communicate with anyone. And that was frustrating. After I started with speech therapy and I could speak to people, this has improved.'}

Communication is a major function of the face and neck. Tilting the head, facial expressions such as smiling and frowning, and above all, speech, laughter and other emotional expressions are all part of human interaction (Boone \& McFarlane, 1994). The sound of one's vocalisation often mirrors one's internal emotional state (Boone \& McFarlane, 1994). It seems as though patients who are able to communicate verbally do better emotionally and psychologically than those who have to rely on writing. A loss of communication may also signify a loss of closeness and love. We create closeness through communication (Ventegodt, Andersen, Kromann \& Merrick, 2003). The importance of verbal communication to quality of life confirms the role of the speech-language pathologist in providing intervention that will enable the patient to achieve intelligible speech.

\section{Work/finances}

The ability to work had a major impact on the partici- pants' quality of life. Because he has not been able to work, Participant 1 experienced feelings of worthlessness and not being able to make a contribution to life. He said:

'People see me as a sort of parasite that wants to live on other people. People also see me as someone that has nothing to contribute. Without speech I am useless to the company, because I have to speak with a radio control as well as to clients.'

In contrast, Participant 2 experienced pride and found satisfaction in his ability to continue his career and provide for his family. This impacted positively on his self-image. He was able to go back to work two months after the operation. This fact contributed to his feeling of pride. The ability to communicate verbally allowed Participant 2 to resume his work and that enhanced his process of integration into the community. This was not possible for Participant 1 who was non-verbal.

\section{Social well-being}

\section{Perception of other peoples' reactions towards them}

Both participants were very perceptive with regard to the reactions of people towards their "disability". At the time of the interview Participant 1 was more intensely sensitive than Participant 2 . The fact that Participant 1 was interviewed only six weeks after his total glosso-laryngectomy, may explain why his sensitivity towards the reactions of people was more intense than those of Participant 2. Participant 1 preferred to be alone and actively avoided people, although he longed to make contact with people as he did before. His inability to communicate verbally and the abnormal way in which he eats caused reactions from people in his environment. Participant 1 said:

'I am shy. Yesterday the wife of the guy lying in the room opposite me came to visit him. The way in which I eat is funny because I must place the food at the back of my mouth, and it upsets me if people watch me while I'm eating. There is a lady in the ward that calls me a "rude bastard" because I'm not talking to anyone - until I wrote her a message to explain why I'm not talking to anyone. All strange (might be a better translation: unfamiliar) people think I'm rude. They accept my condition but are clearly uncomfortable.'

Seven years after his total glosso-laryngectomy, Participant 2 
has possibly come to terms with these reactions, although he contradicted himself about this issue during the interview. He was still very self-conscious while eating. Initially, his altered way of speech also drew attention. Participant 2 said:

'I am very self-conscious and I think people are looking at me - that is my problem. Or when I speak, people look at me in a funny way. When I speak, people stare at me, especially children. It did bother me, but not any more. Unfamiliar people do not bother me any more when I interact with them. They go on as if nothing is wrong with me. In other words they look past the problem.'

\section{Isolation}

Both participants experienced a degree of isolation and of being "separate" from other people. Participant 1 possibly experienced this more intensely, as he was not able to communicate verbally. He said:

\section{I don't have a problem to write what I want to say. If people only wanted to read! It is the only way to tell people that although I do not have a tongue or a voice, I still am a person with feelings, trying to share those feel- ings.'}

Participant 2 was also isolated initially, but over the years has gradually returned to the community. Only after seven years did he have the courage, for example, to attend a church camp. The fact that Participant 2 could communicate verbally facilitated the process of reintegration into the community. He could resume his work and communicate with family and friends. Participant 2 said:

\begin{abstract}
'In the beginning I didn't take part in any activities. But that has now changed. One must never isolate one self I have tried that, but it didn't work. Because I couldn't speak, I avoided going to church for a whole year.
\end{abstract}

\section{Acceptance and support}

Participant 1 struggled to cope due to a very limited support structure. He expressed his wish for his mother's acceptance and support more than once during the interview. Although his sister, ex-fiancée and ex-wife supported him, he expressed the longing for support from his mother. He also did not receive support from his children, previous colleagues or friends. Participant 1 said:

\section{'Most family members and friends accept me as I am. But there are others that do not want to understand. Like my mother, for example. She is very impatient with me. If I write her a message, I can see that she does not really want to read it. If I snap my fingers to attract her atten- tion, she says that she is not a dog that I can snap my fingers at.}

Participant 2 reported that his wife, family and friends accept him as he is. He had persistent support from his wife since the time of diagnosis. She supported him every step of the way in all practical and emotional aspects. Two of his three children, people from his church and neighbourhood, his general practitioner and colleagues provide a great deal of support. His employer accommodated him and supported him in the process of resuming his work after the operation. Participant 2 has possibly coped with all the changes because of his excellent support structure. He said:

'I went on a church camp in February for the first time, where the people treated me as a normal human being.
They treated me like a normal human being. It is wrong If people do not treat you as a normal human being. But in general people accept me for who I am. Nobody rejects me. My family has supported me physically and emotionally. No one rejected me. We go on holiday together when we can. One must have support - it is very important.'

Social support can be defined as the resources provided to people through their interactions with other people. Morton (1995) stated that lack of adequate family support has a negative impact on quality of life. Head and neck patients should be provided with the necessary support services early in the process, as well as with follow-up later in the process (Casper \& Colton, 1993). Support should include medical as well as psychological help (Harrison, 1983). As psychological distress is common in patients with head and neck cancer, psychosocial support has a role in reducing this distress (Hutton \& Williams, 2001). In addition, social support, from either family members or groups, can help restore some of the loss of control that cancer patients may experience (Sheridan \& Radmacher, 1992). Thus, they need to be provided with as many opportunities as possible to increase their sense of control. Vickery et al. (2003) further stated that the physical and psychological stresses from head and neck cancer could also be substantial for patients' partners. Partners may in fact report greater distress than patients may on some quality of life scales (Vickery et al., 2003). Partners or significant others may also go through a process of grief while accepting the changes in the person close to them. Support services should always be available to the patient and his or her significant others. Structured education and support-group based services play a major role in meeting information and supportive needs (Todd, Roberts \& Black, 2002).

\section{Emotional/Psychological well-being}

\section{Changed self-image}

Self-image refers to our overall perception of ourselves, and the way we feel about how others see us (Appleton \& Machin, 1995). Both participants experienced feelings of being "different" from other people. Participant 1 expressed the changes in his way of eating and communicating as being the causes of this perception of being "different". Change in physical appearance is another reason the participants experienced themselves as "different". Participant 1 stated:

\section{'I get a fright each time I look in the mirror'.}

Participant 2 insisted that people should treat him as "a normal human being". These words may suggest that he still has not completely accepted himself as "normal" or that he constantly needs affirmation that he is not "abnormal". Even though Participant 2 acquired the ability to communicate verbally, the glossectomy speech and tracheoesophageal voice does not sound normal. This fact may contribute to his feeling of being different.

Facial appearance is part of our overall self image and an important entity in establishing interpersonal relationships. The face is the most visible bodily area where all the major senses are located, as well as being the area of a person's selfidentity. Disfigurement in this area has far-reaching implications for a patient's psychosocial interaction with the world and adversely affects the patient's self-esteem (Appleton \& Machin, 1995). Gamba et al. (1992) suggested that a head and neck cancer patient's self-concept should be studied as a possible diagnostic parameter to identify individuals at high risk for psychosocial maladjustment. The fact that patients "no longer recog- 
nise themselves" was the most frequently expressed reason why patients felt that treatment for head and neck cancer was not worth the effort (Gamba et al., 1992).

The issue of identity needs to be carefully considered in total glosso-laryngectomy patients. They may experience themselves as "changed" or "different" not only because of the facial disfigurement but also due to the loss of voice. The voice of a person is as characteristic of the person as the face is. Facial disfigurement, loss of voice and the inability to communicate are all closely bound to a sense of loss of identity. Speech-language pathologists should be aware of how the patient's self image has altered following total glosso-laryngectomy. They should also be aware of the patient's resources for coping and of any grief reactions that are evident. The patient should be referred for appropriate counselling if needed (Casper \& Colton, 1993).

\section{Adjustment}

Adapting to a major change in one's life such as a total glossectomy or total glosso-laryngectomy is a process that may take many years and even a lifetime. Participant 1 was still in the beginning phase of the process of adapting to a new life, and did not yet posses the skills to help him cope with all the changes in his life. He was not even prepared for the changes that were imposed on him by the surgery. He said:

\section{'I feel like a baby in an unknown world. I have to learn to crawl before I can walk again.'}

Participant 2, who had the surgery seven years prior to the interview, reported that his depression decreased over the seven years as he adapted to his situation. He had come to terms with many of the changes in his life, including an altered way of eating and communicating. He described this coming to terms as a process that took place over the years. He went through different phases of growth towards acceptance. The gradual acceptance by family and friends could also promote patient adaptation as is evident for Participant 2 . He said:

\begin{abstract}
'In the beginning I didn't take part in any activities. I was disheartened and pitied, myself But this has now changed. Never lose hope. I was extremely hopeless at some stage. If it wasn't for my wife, the speech therapist 'and the Grace of God, I wouldn't have been here today. Never pity yourself It doesn't work. Life is tough. It does not help to sit in the ashes. One should never give up hope! One should live into the future, not in the past. Never isolate yourself I did that and it didn't work.'
\end{abstract}

Head and neck cancer and its treatment place significant adaptive demands on patients and their families (Katz et al., 2003). During the first year of treatment, almost a third of head and neck cancer patients reported having mood disorders (Petruson, et al., 2003). Casper and Colton (1993) explained that some individuals with head and neck cancer could initially withdraw from social contact, especially if people show evidence of discomfort with their condition. This withdrawal is a normal stage in the process of accepting changes in their self-image or functional abilities. Hutton and Williams (2001) reported that depression tends to decrease with time after the onset of head and neck cancer, and also decrease with increasing age. Morton (1995) reported life-satisfaction scores in head and neck cancer patients to increase over time.

\section{Quality of life}

The participants were asked questions about their perception of changes in their quality of life. Participant 1 felt that his quality of life has drastically decreased since the surgery. He was still mourning the loss of communication and the ability to eat normally. He said:

\section{'Before the operation I could do so many things that are no longer possible.'}

Participant 2 on the other hand felt that his quality of life after the surgery was better than his quality of life shortly prior to surgery. Since the operation he has adapted his life to accommodate his changed abilities. He has again found meaning in life and was continuing to improve his quality of life by expanding social contact.

Quality of life as globally assessed by patients does not directly correlate with measures of physical function, but appears to depend on psychological, spiritual, and existential factors and also support systems (Simmons, Bremer, Robbins, Walsh \& Fischer, 2000). Kim and Alvi (1999) found that 94\% of patients who had been diagnosed with cancer, feared death, metastasis, recurrence, and the loss of the ability to swallow, speak or breathe in the usual manner. Uncertainty over the future and the reality of the loss they experienced impact on the subjective perception of quality of life. Hopefulness and having a life purpose help to balance the worse outcomes (Dow, Ferrell, Leigh, Ly \& Gulasekaram, 1996).

\section{Additional themes}

\section{Pre-operative counselling}

Both participants received very little pre-operative information or counselling. According to both participants the absence of pre-operative counselling impacted negatively on their post-operative recovery and quality of life. Adjustment to the major changes in self image and functional ability was compromised because they were not empowered to prepare themselves for post-operative changes.

Participant 1 expressed his shock at the way his body was changed when he woke up after the operation. He was also not aware of the fact that he was going to lose his voice. Participant 1 said:

'I was upset, but what does it help? When I woke up I saw there was a hole in my throat. The hole in my chest was just a big shock; nobody told me that there is going to be a hole in my chest.'

Participant 2 received some information regarding swallowing and speech from his surgeon, but also did not receive any counselling from other members of the multidisciplinary team such as the speech-language pathologist. He said:

'He told me it was going to be a big operation. He explained to me what to expect, also with regard to speech and swallowing. He told me that I won't be able to speak normally again.'

Shared decision making (SDM) is currently recommended as a standard of care, especially when there are alternative treatments available or when there is uncertainty about the outcomes of treatment (Mandelblatt, Krelling, Figeuriedo \& Feng, 2006). According to Fayers and Machin (2000) many patients and patient support groups demand to be given full information about the consequences of the disease, its treatment and the impact on aspects of quality of life. Patients should also be able to express their opinions (Fayers \& Machin, 2000). Street (1997) found that patients with breast cancer who had more actively participated in their consultations with their doctors, particularly in 
terms of offering opinions, assumed more responsibility for treatment decisions.

Davidson et al. (1993) stated that candidates for total glossectomy should be carefully considered and that pre-operative psychiatric evaluation could assist the surgeon in making apt decisions regarding treatment. Newell, Ziegler, Stafford and Lewin (2004) found that head and neck cancer patients need individualised pre-treatment information in an appropriate environment and that there should be more than one opportunity for patients to discuss their options. Thereby the patient would be able to make an informed decision to undergo surgery.

If the experiences of the two participants in this study are a true reflection of the nature of the local service delivery model, the relevant professionals need to take a serious look at the issue of pre -operative counselling, shared decision making and informed consent before glossectomy and glosso-laryngectomy in South Africa. Pre-operative assessment and counselling by a multidisciplinary team including the surgeon, psychologist, social worker, physiotherapist and speech-language pathologist would be the ideal. The team should prepare the patient and family for what the operation entails and how it will affect post-operative functioning.

\section{Role of the speech-language pathologist}

Both participants highly valued the contribution of the speech language pathologist to their rehabilitation and quality of life. The speech-language pathologist has knowledge of the effects of total glosso-laryngectomy on swallowing and speech and also insight into the emotional and social effects of altered ways of swallowing and communication and is therefore equipped to support patients. By providing pre- and post-operative counselling as part of a multi-disciplinary team and speech and swallowing intervention, the speech-language pathologist can make a major contribution to improve quality of life for patients with a glossectomy or glosso-laryngectomy.

\section{CONCLUSION}

Total glosso-laryngectomy represents the extreme of extensive head and neck cancer surgery. Both participants expressed their appreciation of being alive, but stated that their quality of life was greatly affected by the surgery. The results of this study showed that they tend to feel isolated and different from other people. They are very sensitive to the reaction of others towards their physical appearance and their changed way of eating and speaking. Functional speech, as well as acceptance and support from significant others appear to be the most important protecting factors of quality of life. Time appears to be a contributing factor to adapting to physical and functional changes.

An important outcome of this study is the raised awareness that shared decision making and pre-operative counselling of the patient and significant others in our local service delivery context needs to be addressed. A multidisciplinary team which includes the surgeon, speech-language pathologist, physiotherapist, psychologist and social worker should prepare the patient and significant others for the consequences of surgery for head and neck cancer. To make, an informed decision regarding surgery, it is crucial that the patient is aware of all the effects of total glosso-laryngectomy on physical appearance, swallowing, and communication.

The choice to undergo surgery remains with the person with head and neck cancer. In the case of Participant 2 the choice to undergo a glosso-laryngectomy to cure him from cancer was a worthwhile decision. After seven years he was still alive and was leading a fulfilled life in spite of the changes in functional ability. In the case of Participant 1 there is no easy answer. Participant 1 passed away 6 months after the interview due to massive local recurrence and metastases.

\section{REFERENCES}

Appleton, J. \& Machin, J. (1995). Working with oral cancer. Oxon: Winslow Press Ltd.

Berg, B.L. (2007). Qualitative research methods for the social sciences ( $6^{\text {th }}$ ed.). Boston: Pearson.

Boone, D.R. \& McFarlane, S.C. (1994). The voice and voice therapy. New Jersey: Prentice Hall.

Casper, J.K. \& Colton, R.H. (1993). Clinical manual for laryngectomy and head and neck cancer rehabilitation. California: Singular Publishing Group, Inc

Chen, A.J., Frankowski, R., Bishop-Leone, J., Hebert, T., Leyk, S., Lewin, J. \& Goepfert, H. (2001). The development and validation of a dysphagiaspecific quality of life questionnaire for patients with head and neck cancer. Archives of Otolaryngology Head and Neck Surgery, 127, 870-876.

Davidson, J., Brown, D. \& Gullane, P. (1993). A re-evaluation of radical total glossectomy. The Journal of Otolaryngology, 22(3), 160-163.

De Vos, A.S. (Ed.) (2002). Research at grass roots, (2 ${ }^{\text {nd }}$ ed.). Pretoria: Van Schaik.

Dow, K.H., Ferrell, B.R., Leigh, S., Ly, J. \& Gulasekaram, P. (1996). An evaluation of quality of life among long-term survivors of breast cancer. Breast Cancer Research and Treatment, 39 (3), 261-273.

Fang, F.M., Tsai, W.L., Chien, C.Y., Chiu, H.C., Wang, C.J., Chen, H.C. \& Hsiung, C.Y. (2005). Changing quality of life in patients with advanced head and neck cancer after primary radiotherapy or chemoradiation. Oncology, 68, 405-413.

Fayers, P.M. \& Machin, D. (2000). Quality of Life: Assessment, Analysis and Interpretation. New York: John Wiley and Sons.

Ferlito, A., Rogers, S.N., Shaha, A.R., Bradley, P.J. \& Rinaldo, A. (2003). Quality of life in head and neck cancer. Acta Otolaryngology, 123, 5-7.

Gamba, A., Romano, M., Grosso, I.M., Tamburini, M., Cantu, G., Molinari, R. \& Ventafrida, V. (1992). Psychosocial adjustment of patients surgically treated for head and neck cancer. Head and Neck, May/June, 218-223.

Gift, H.C. \& Atchison, K.A. (1995). Oral health, health, and health-related quality of life. Medical Care, 33 (11), 557-577.

Harrison, D. (1983). The questionable value of total glossectomy. Head and Neck Surgery, 6, 632-638.

Harrison, L.B., Ferlito, A., Shaka, A.R., Bradley, P.J., Genden, E.M. \& Rinaldo, A. (2003). Current philosophy on the management of cancer of the base of the tongue. Oral Oncology, 39, 101-105.

Henderson, J.M. \& Robert, A. (1997). Suicide in head and neck cancer patients Journal of Oral Maxillofacial Surgery, 55, 1217 - 1221

Hutton, J.M. \& Williams, M. (2001). An investigation of psychological distress in patients who have been treated for head and neck cancer. British Journal of Oral and Maxillofacial Surgery, 39, 333-339.

Katz, M.R., Irish, J.C., Devins, G.M., Rodin, G.M. \& Gullane, P.J. (2003). Psychological adjustment in head and neck cancer: The impact of disfigurement, gender and social support. Head and Neck, February, 103112

Kendall, K. \& Leonard, R. (1999). Recent advances in the assessment and treatment of dysphagia. Current Opinion in Otolaryngology and Head and Neck Surgery, 7, 107-111.

Kim, M.K. \& Alvi, A. (1999). Breaking the bad news of cancer: The patient's perspective. Laryngoscope, 109, 1064-1067.

Major, M.S., Bumpous, J.M., Flynn, M.B. \& Schill, K. (2001). Quality of life after treatment for advanced laryngeal and pharyngeal cancer. Laryngoscope, 111, 1379-1382.

Mandelblatt, J. Krelling, B. Figeuriedo, B. \& Feng, S. (2006). What is the impact of shared decision making on treatment and outcomes for older woman with breast cancer? Journal of Clinical Oncology, 24 (30), 49084913. 
Morton, R.P. (1995). Life-satisfaction in patients with head and neck cancer. Clinical Otolaryngology, 20, 499-503.

Morton, R.P. (2003). Studies in the quality of life of head and neck cancer patients: Results of a two year longitudinal study and a comparative crosssectional cross-cultural survey. Laryngoscope, 113, 1091-1103.

Neumann, W.J. (2000). Social research methods: Qualitative and quantitative approaches $\left(4^{\text {th }}\right.$ ed.). Boston: Allyn and Bacon.

Newell, R., Ziegler, L., Stafford, N. \& Lewin, R.J. (2004). The information needs of head and neck cancer patients prior to surgery. Annals of the Royal College of Surgeons of England, 86, 407-410.

Patton, M.Q. (1990). Qualitative evaluation and research methods ( $2^{\text {nd }}$ ed.). London: Sage Publications.

Petruson, K.M., Silander, E.M. \& Hammerlid, E.B. (2003). Effects of psychosocial intervention on quality of life in patients with head and neck cancer. Head \& Neck, July, 576-584.

Pretorius, J.P. (2004). Quality of life. Paper presented at the Multidisciplinary Palliative Care Conference. March CSIR Conference Centre, Pretoria.

Ruhl, C.M., Gleich, L.L. \& Gluckman, J.L. (1997). Survival, function, and quality of life after total glossectomy. Laryngoscope, 107, 1316-1321.

Shah, J.P. (1996). Head and Neck Surgery ( $2^{\text {nd }}$ ed.). London: Mosby-Wolfe.

Sheridan, C.L. \& Radmacher, S.A. (1992). Health Psychology: Challenging the Biomedical Model. New York: John Wiley \& Sons, Inc.
Simmons, Z., Bremer, B.A., Robbins, R.A., Walsh, S.M. \& Fischer, S. (2000) Quality of life in ALS depends on factors other than strength and physical functioning. Neurology, 55, 388-392.

Street, R.L. (1997). Patient participation in deciding breast cancer treatment and subsequent quality of life. Medical Decision Making, 17 (3), 298-306.

Terre Blanche, M. \& Durheim, K. (1999). Research in practice: Applied methods for social sciences. Cape Town: UCT Press.

Todd, K., Roberts, S. \& Black, C. (2002). The living with cancer education programme. I. Development of an Australian education and support programme for cancer patients and their family and friends. European Journal of Cancer Care, 11, 271-279.

Ventegodt. S., Andersen, N.J., Kromann, M. \& Merrick, J. (2003). Quality of life Philosophy II: What is a human being? The Scientific World Journal, 3, 1176-1185.

Vickery, L.E., Latchford, G., Hewison, J., Bellew, M. \& Feber, T. (2003). The impact of head and neck cancer and facial disfigurement on the quality of life of patients and their partners. Head and Neck, April, 289-296.

Walter, J.J. \& Shannon, T.A. (1990). Quality of life: The new medical dilemma. New York: Paulist Press.

World Health Organisation. (1997). WHOQOL: Measuring quality of life. Geneva: WHO.

World Health Organization. (2007). International classification of functioning and disability: A new release from WHO. Retrieved on 2007/08/07 from the World Wide Web: http:/www.who.int/inf-pr-1999/en/note99-19.html. 


\section{APPENDIX A}

\section{Interview Schedule for Semi-Structured Interviews}

\section{GENERAL NFORMATION}

What surgery did you receive?

When did it take place?

Did you have any other treatment?

Was it before or after surgery?

How were you informed of the diagnosis of cancer?

Did you have a choice in the type of treatment you could receive?

Were the implications/consequences of the surgery discussed with you?

\section{PHYSICAL WELL-BEING}

How did the surgery affect your quality of life in terms of your general physical well-being?

Can you independently perform daily activities since the surgery?

Did you experience any difficulties in breathing?

Did you experience pain?

Do you have sufficient energy since the surgery to perform daily activities?

Do you have full range of movement in the shoulder and neck areas?

Are there any other physical problems you experienced since the surgery?

\section{FUNCTIONAL WELL-BEINC}

\section{FEEDING}

What were the effects of the surgery on your ability to eat and to swallow?

Describe how you eat

Did your diet change since the surgery?

Did your appetite decrease after surgery?

Did you experience any weight loss after surgery?

Did your experience of eating in a social context change since the surgery?

\section{COMMUNICATION}

What were the effects of the surgery on your ability to communicate?

How do you communicate with other people?

Do you think that people understand your speech?

How do your communication abilities affect your interaction with people?

How do you feel about your way of communication?

\section{WORK AND FINANCES}

What job did you have before surgery?

Could you go back to work?

Did the surgery or your physical health cause financial problems?

\section{SOCIAL WELL.BEIMG}

\section{SOCIAL INTERACTION AND FAMILY RELATIONSHIPS}

How did the surgery affect your social interaction?

How did it affect family relationships?

Do you take part in less social activities since the surgery?

How do family and friends react during social interaction?

How do you feel about these reactions?

\section{SUPPORT}

Who supported you since you were diagnosed with cancer?

Did your family support you physically and emotionally since the surgery?

Which other medical professionals except your surgeon were involved with you before the surgery and how did they help you?

. Which other medical professionals except your surgeon were involved with you after the surgery and how did they help you?

\section{EMOTIONALIPSYCHOLOGICAL WELL-BEING}

What were the effects of the surgery on your emotional or psychological well-being?

What emotions did you or do you experience since the surgery?

How does your quality of life before surgery compare to your quality of life after the surgery?

How would you describe your life as a whole now?

How do you see your future?

If you could have the choice again, would you decide to undergo this operation? 